\title{
Altamira, corresponsal de Costa
}

In: Bulletin Hispanique. Tome 68, №3-4, 1966. pp. 357-364.

Citer ce document / Cite this document :

Cheyne G. J. G. Altamira, corresponsal de Costa. In: Bulletin Hispanique. Tome 68, №3-4, 1966. pp. 357-364.

http://www.persee.fr/web/revues/home/prescript/article/hispa_0007-4640_1966_num_68_3_3882 


\section{ALTAMIRA, CORRESPONSAL DE GOSTA}

Ignoro la extensión exacta de la correspondencia cruzada entre Joaquín Costa (1846-1911) y Rafael Altamira (1866-1951), pero he podido reunir hasta ahora una cuarentena de cartas, escritas entre los años 1891 y 1906, aparte de las cuatro que se hallan en el Archivo Histórico Nacional (Diversos. Titulos y Familias, caja 103). Es un epistolario sobrio, de intelectuales intensamente entregados a sus tareas, sin tiempo casi para el detalle doméstico o para asuntos puramente personales. Pero aunque sobrio, opino que no tiene nada de frío; además de una absoluta franqueza, base evidente de su amistad, se trasluce en él la admiración de Altamira por Costa, a quien consideraba como maestro, y el alto aprecio de éste para el historiador alicantino.

Los veinte años que separaban a ambos quedan borrados ante la común preocupación : el estudio de los problemas nacionales con el fin último de buscarles remedio. Costa fue más atrevido en este intento, ya que llegó a lanzarse de lleno en la vida política del país, actuación que Altamira comenta y aplaude en alguna de estas cartas, aunque haciendo constar su falta de afición a la política activa.

Espero aumentar esta colección de cartas en el curso de mis presentes trabajos sobre Joaquín Costa. Hasta conseguir esto, y publicar entonces lo que, a mi entender, será un muy interesante epistolario, quiero ofrecer las seis cartas que siguen, con ocasión del centenario del nacimiento de Altamira. Su mayor interés estriba no sólo en la información que ofrecen sobre detalles bibliográficos (algunos inéditos) y los comentarios espontáneos sobre algunas obras en el momento mismo de su producción, sino también en la descripción de los intentos de llevar a cabo, a finales del siglo xIx, la extensión universitaria, cuya importancia sigue siendo tema de actualidad mundial.

Finalmente, quisiera excusarme por la extensión de las notas que acompañan esta correspondencia. Las muchas alusiones a personas y ocurrencias de la época me obligan a ofrecer una información que creo consumiría demasiado tiempo del lector si se viera precisado a buscarla por sí mismo, ya que se halla desperdigada en numerosos libros y revistas.

Museo de Instrucción Primaria

Calle de Daoíz y Velarde.

8 de enero, 1892

Mi querido amigo D. Joaquín : Muchísimas gracias por su juicio y obser- 
vaciones sobre mi libro ${ }^{1}$ : otras más se le ocurrirán a V. sin duda, en el resto de las páginas, y le agradeceré mucho me las comunique para aprovecharlas en la segunda edición del libro que, por ser la primera corta (500 ejemplares) y gratis, no tardará mucho.

En cuanto a mi discurso (sic) sobre Chao ${ }^{2}$, piensa V. bien. Fue una debilidad mía, cometida con la mejor intención. Los chicos de la Juventud (a la cual, en efecto, nunca he pertenecido) me invitaron a la velada y fui. Contaban ellos con discursos de González Serrano ${ }^{3}$, Salmerón, etc.; pero no sólo no los tuvieron, sino que, olvidándose de la persona a cuya memoria estaba dedicada la reunión, $\mathrm{y}$ ante la cual desaparecía la entidad de la Juventud, se negaron los señores del Directorio y otros cabezas a ir al Teatro. La noticia vino momentos antes de empezar la reunión y a mí, confieso que me desagradó mucho. Entonces, comenzaron los jóvenes a solicitar, con gran ahinco, la cooperación de alguien que no fuera de la Juventud, para que la velada no quedase reducida a los desahogos de dos o tres muchachos que no sabian siquiera lo que Chao habia hecho y que, por tanto, no hablaron de él.

Todas estas circunstancias, me obligaron a ceder; pero la aventura tiene carácter esporádico y sin bis.

Me escriben, sobre el libro, Webster *, Clarin, Posada ${ }^{\star}$ e Hinojosa. Lo

1. Se refiere a La Enseñanza de la Historia (1891). La segunda edición corregida y considerablemente aumentada se hizo en Madrid en 1895 por Victoriano Suárez.

2. Eduardo Chao (1821-1887), hombre de formación krausista, fue de la Junta Directiva de Accionistas fundadores de la Institución Libre de Enseñanza. Ministro de Fomento en el Gobierno republicano presidido por Figueras en 1873, cre6 la Comisión del Mapa Geologico de la Península y la Junta del Canal Imperial de Aragón y dictó varias disposiciones sobre carreteras y ferocarriles así como importantes decretos referentes a educación, siendo el más significativo el de la abolición del . Juramento político . $^{2}$

Fue historiador, y su mayor obra fue su colaboración en la continuación de la Historia de España de Mariana.

3. Urbano González Serrano, miembro del partido republicano centralista, krausista con tendencias al positivismo. Fue profesor de Instituto, explicando Psicologfa, Lógica y Etica en el de San Isidro de Madrid, y fue sustituto ocasional de Salmerón en la cátedra de Metafísica de la Universidad madrileña. Publicó obras de carácter filosofico, especialmente de psicologfa, derivando hacia la sociologia y la entonces llamada psicología colectiva $\triangleright$. Sus estudios de critica literaria fueron coleccionados en un libro titulado Estudios críticos, de los cuales fue el más notable un estudio sobre Goethe (1878).

4. Rev. Wentwooth Webster (1827-1907). Filologo inglés especializado en la historia y lengua vascas. Fue miembro correspondiente de la Real Academia de la Historia de Madrid. Colaboró en el Bulletin de la Socièté des Sciences et Arts de Bayona, The Quarterly Review, Londres, etc., y publico varios libros entre los que se hallan Basque legends (London, 1877) y Spain (London, 1882).

5. Adolfo González Posada (1860-1944). Catedrático de Derecho Politico y Administrativo de la Universidad de Oviedo.

Mantuvo un constante interés en cuestiones de educación y de reforma social $y$ fue, de 1904 a 1924, el Director de los Servicios de Información, Bibliografía y Acción Social del Instituto de Reformas Sociạles presidido por Gumersindo de Azcárate.

En 1910 fue nombrado catedrático de Derecho Municipal comparado en la Universidad de Madrid, pasando luego a ser catedrático de Derecho Polftico en la misma Universidad, y llegando a ser el Decano de la Facultad de Derecho. 
envio a Hübner y a dos revistas alemanas, además de la inglesa que me indicó Webster.

Don Francisco mucho mejor. Grandes recuerdos de todos para V. Yo le deseo un feliz nuevo año, y le envio un cordial abrazo.

Suyo,

R. Altamira. -

Oviedo 22 de octubre 98

Querido Costa : Mil perdones por no haber contestado antes a su gratísima y sustanciosa del 8. Llevo, desde el 1, una temporada de ahogo de trabajo, entre la terminación (notas bibliográficas, compulsa etc.) de la Psicología del pueblo español ${ }^{7}$, la traducción de Fichte ${ }^{8}$, el planteamiento aquí de la "extensión universitaria ${ }^{\circ}$ especialmente para obreros (por acuerdo unánime del Claustro) $\mathrm{y}$ otras preocupaciones. La « extensión " comenzará a funcionar en Noviembre. Los de la Facultad de Ciencias nos ayudarán mucho. Habrá dos clases de lecciones : primera de vulgarización y educación, para obreros y público bajo; $2^{\circ}$ de cultura intensa, v. gr. Alas : corrientes filosóficas modernas; Mur $^{10}$ : la geometría de $n$ dimen-

En 1919 el gobierno español le nombro su delegado en la Sociedad de Naciones y como tal asistió a la Conferencia Internacional del Trabajo.

Hizo numerosos viajes por Hispanoamérica, dando cursillos y conferencias.

Escribí obras de derecho, obras sobre educación y gran cantidad de artículos en los peribdicos y revistas de su tiempo.

6. Emil Hübner (1834-1901). Catedrático g epigrafista alemán entre cuyas numerosas obras se hallan : Inscriptiones Hispaniae (Berlin, 1869), Inscriptiones christianae (Berlín, 1871 y 1900), Arqueología de España (Barcelona, 1888), Monumenta linguaie ibericae (Berlín, 1893).

7. De este libro se hicieron dos ediciones : $1^{\text {a }}$ edicion : Psicologia del pueblo español, Madrid (Fernando Fé), Barcelona (Antonio López), 1902. Vol. II de la Biblioteca Moderna de Ciencias Sociales, publicada bajo la dirreción de Alfredo Calderón y S. Valentí Camp ; 2 edición, corregida y muy aumentada, Barcelona (Ed. Minerva S. A.) s. 1. [1918] (Biblioteca de Cultura Moderna y Contemporánea). En 1898 no lleg6 a publicarse, como puede deducirse de la lectura de la carta de 29 marzo 1900.

8. Esta traducción se publicó en La España Moderna Año 110,124 (Abril 1899), 41-55; 125 (Mayo 1899), 96-122; 126 (Junio 1899), 100-129; 128 (Agosto 1899), 81-94; 129 (Septiembre 1899), 129-145; 130 (Octubre 1899), 110-126; 131 (Noviembre 1899), 11 7-131; Año 12॰, 135 (Marzo 1900), 80-95 ; 137 (Mayo 1900), 118133 ; 140 (Agosto 1900), 127-139; 143 (Noviembre 1900), 35-66. Tambien se publicó esta traducción como un volumen suelto, publicacion que fue anunciada en la seccion Obras Nuevas de 10 Enero 1901, Año 130, Tomo 145, p. 206.

9. Extensión universitaria. Aunque en años anteriores habia habido ejemplos de educación fuera de la universidad, por parte de elementos universitarios, estos esfuerzos no adquirieron carácter sistemático hasta que en 1898 Leopoldo Alas recogió ideas expresadas por $R$. Altamira en su discurso inaugural de aquel año universitario y consiguió que fuera aceptada la iniciativa no sólo en el ámbito universitario sino también en el Seminario y otros organismos docentes.

En Noviembre de 1898, tal como anuncia Altamira en esta carta, estaba la Extensión enteramente planeada y su funcionamiento empezo, sin incidentes y con pleno éxito.

Para más detalles, el libro de Aniceto Sela La Educoción Nacional. Hechos e Ideas. Madrid (Victoriano Suárez), 1910, es de incalculable valor.

10. José Mur y Ainsa (1870 - D). Catedrático de Geometría analítica en la Universidad de Oviedo (1896-1914) antes de ocupar el mismo puesto en las de Valencia y Barcelona. Tomo parte activisima durante quince años en los trabajos de 
siones (para un público muy limitado). Además, excursiones a los centros obreros (Gijón, Mieres, Langreo, etc.) para dar conferencias muy familiares, experimentales, etc. Sela 11 hará, con el aparato de proyecciones, viajes a Francia y Suiza y por España; yo, Leyendas de la Historia de España, etc...

Su artículo de El Liberal 18 nos ha gustado a todos muchísimo, por su valentía, su sinceridad... y su miga. Hoy lo reproduce aqui La Unión Republicana. ¿Vio V. un artículo de Morote acerca de V. en El Mercantil valenciano? $E l$ Globo ${ }^{13}$ nos ha pedido parecer (en concepto de futuros... imperfectos) a Buylla 14, Posada, Sela y este humilde servidor. Por desgracia nuestra corriente va a estrellarse en otra de a acción $\triangleright$ que se anuncia y de la que temo malas consecuencias, a pesar del optimismo de algunos. Si fracasara, creo que acabaría por condenarse la nuestra.

Mi libro, creo saldrá en Diciembre. El primer capítulo \& Problema actual del patriotismo », salió en el número de este mes de « La España Moderna ». El segundo (la Psicologia...) lo remití ayer a la misma Revista.

Como antes dije, estoy traduciendo a Fichte, con ayuda de la versión francesa, que no siempre es fiel. El ejemplar de ésta que yo tenía es del Museo, y lo devuelvo con Sela (que irá a esa pronto) para que V. lo maneje. Ya pedí yo otro.

¿Tardará mucho su libro de V.?

En la a escuela práctica » hacen este año los chicos de mi sección « Derecho consuetudinario de Asturias *. Creo que llegaremos a reunir gran cantidad de datos utilizando estos tres medios : dépouillement de libros y revistas asturianos; interrogatorios escritos; excursiones para ver y conversar con aldeanos, curas, etc.

Nada más por hoy, porque vienen a buscarme para ir de excursión ${ }^{15}$.

Extensión universitaria de la Universidad de Oviedo, dando clases de vulgarización científica sobre matemáticas, física, química y ciencias sociales no solamente en Oviedo, sino en centros obreros de distintas ciudades y pueblos asturianos.

11. Aniceto Sela y Sampil $(1863$ - $)$. Catedrático de Derecho Internacional en la Universidad de Oviedo, a la que llego después de haber ejercido la misma cátedra en Valencia desde los 25 años. Habla sido discípulo de Giner de los Ríos y profesor de la I. L. E.

Fue secretario de la Junta de Extensión Unioersitaria de Oviedo, sobre cuyo desarrollo durante los 10 primeros años escribio en el libro ya citado en nota 9.

En 1919 fue Director General de 1s Enseñanza. Sus escritos versaron principalmente sobre cuestiones de educacion.

12. La colección de El Liberal correspondiente al año 1898 de la Hemeroteca Municipal de Madrid es incompleta y muchos de los números existentes se hallan mutilados. Me ha sido imposible descubrir el artículo a que se hace referencia en esta carta.

13. El Globo, Diario politico ilustrado de Madrid.

14. Adolfo Builla y Alegre (1850-1927). Catedrático de Economía Política y Hacienda Pública en la Universidad de Oviedo y hombre de ideas socialistas y republicanas, de las que no hacfa ningón secreto.

Cré la Escuela Práctica de Estudios Jurídicos y public6 varias obras sobre economía y educación universitaria.

Su apellido aparece escrito en diversos documentos ora con i latina, ora con $y$ griega.

15. Las excursiones formaban parte del programa de la Extensión unioersitaria. En ellas se visitaban centros artísticos y arqueologicos. 
Recuerdos a Tomás ${ }^{16}$ y a Ducay ${ }^{17}$, y para V. de todos. Suyo siempre afmo.

R. Altamira.

Sr. D. Joaquín Costa.

Oviedo 10 enero 1900

Mi querido amigo :

Mil gracias por su carta acusándome recibo de la Historia ${ }^{18}$. Es un librín modesto publicado con la intención de que, quienes pueden hacerlo bien, se animen y lo hagan, con lo cual seré yo el primero que gane.

Para el tomo $2^{\circ}$ creo sería curioso incluir entre los grabados alguno referente al antipapa Luna ${ }^{19}$. ¿Conserva V. alguna de las fotografías que le enviaron de Edinburgo ${ }^{20}$ ? Creo que una es del busto o mascarilla del célebre paisano de $\mathrm{V}$. ¿Tendría $\mathrm{V}$. inconveniente en prestármela?

No olvido que estoy en deuda con la Revista Nacional ${ }^{21}$. Crea V. que materialmente no he tenido tiempo, con la $H$ istoria, la mudanza y establecimiento de casa (que tengo el gusto de ofrecerle : Campomanes, 8) y la extensión universitaria que en su mayor parte ha pesado sobre mí.

Ruégole salude a Tomás de mi parte, y V. téngame siempre por suyo, buen amigo que muy de veras le estima,

\section{R. Altamira.}

\section{Oviedo 20 Marzo 1900}

Mi querido amigo : Mil gracias por el envio de su capital libro de Recons-

16. Tomás Costa Martínez. Hermano de Joaquín. Después de la muerte de éste emprendio la edición de sus obras bajo la rúbrica general de Biblioteca Costa, edición sobre cuya fidelidad hay que mantener grandes reservas. Durante los años en que se escribieron estas cartas, los dos hermanos vivían juntos $y$ Tomás hacia las veces de secretario.

17. Laureano Ducay. Intimo amigo de J. Costa. Pedro M. Baselga en su librito ¿Quién fue Costa?, Zaragoza, 1918, pone de relieve la devoción de este militar republicano, comandante de infanteria, que no regateó ni tiempo ni sacrificios economicos para servir a su amigo.

18. Historia de España y de la Civilización española.

19. Pedro de Luna, Benedicto XIII (1328 o 1329-1423). Nació en Illueca (Zaragoza) y murio en Peñiscola (Valencia). Siendo cardenal intervino en la lucha entre Urbano VI, elegido papa en Roma, y Clemente VII de Aviñon, declarándose partidario de este último. A la muerte de Clemente VII fue a su vez elegido papa por los cardenales de Aviñon, con lo que se perpetuaron las luchas $y$ disensiones entre los reinos cristianos. Durante su vida como papa se sucedieron en Roma Bonifacio IX, Inocencio VII, Gregorio XII y finalmente, cuando $\mathrm{y}^{2}$ la influencia de Pedro de Luna habla disminuildo notablemente, Alejandro $\mathrm{V}$.

Benedicto XIII murió abandonado de todos pero manteniéndose firme en la defensa de sus derechos.

20. Hubo repetidas ediciones de la Historia de España. En la cuarta edición (Barcelona, 1929) no existe ningún grabado de Benedicto XIII. No es de extrañar que existieran tales grabados en Edinburgo ya que Benedicto XIII fue el creador de la Universidad de San Andrés en Escocia.

21. En estas fechas, Joaquín Costa dedicaba sus esfuerzos a la publicación de la Revista Nacional, 6rgano de la Liga Nacional de Productores, en la que se public6 gran parte de la historia de la Unibn Nacional. En esta revista se publicaron trabajos de Francisco Giner, Rafael M* de Labra y otros hombres representativos. No se encuentra sin embargo ningun articulo firmado por Altamira. 
titución de España 22 . Repartí los ejemplares destinados a los amigos y, por de pronto, va nota anunciadora de la publicación en la Revista critica $^{23}$.

Todos hacemos aquí votos fervientes porque la Unión Nacional sea fructífera. Tememos que no, a pesar de la ciega confianza en $V$. ( $y$, en cierto modo, de las esperanzas que para determinada acción despierta Paraíso 24 , por la calidad de los muchos elementos con quienes han de maniobrar Vds. A lo menos, los de aquí son imposibles. Jamás nos podríamos entender con ellos, ni hacer nada común; y ésta [es la] mayor dificultad para los que, como yo, ayudarian a la obra pero sin hacer política activa, a la que cada vez tengo menos afición. El auxilio intelectual, de propaganda, de enseñanza en el sentido del programa, que podríamos prestar aqui algunos, no lo quieren, ni lo aprecian estos Sres. No sé si es que temen que nos sobrepongamos, o que, como buenos comerciantes y hombres de negocios desprecian en su fuero interno a los intelectuales.

Si la Unión llega al término lógico de su camino : esto es, a demostrar la incompatibilidad del régimen existente con la a regeneración ", y toma posiciones politicas francas, muchos que ven hoy con simpatia el movimiento y no se atreven a dar la cara, irán a él resueltamente. La Unión tiene una ventaja inmensa sobre todos los partidos españoles : un programa concreto. Esa es su gran obra, y la que se impondrá.

Por ahora, desde El Liberal que ha solicitado nuestra colaboración, ayudaremos con fuegos convergentes a esa obra, dentro de nuestro campo pedagógico.

Gracias de nuevo, y sabe es siempre suyo verdadero amigo que le quiere y respeta.

R. Altamira.

Oviedo 29 marzo 1900

Querido Costa : No sólo estoy dispuesto a ayudar al Sr Uria, sino que he dado forma práctica a mi concurso redactando la circular de convocatoria para la constitución de las Cámaras Agrícolas de Asturias, y el proyecto de estatutos ${ }^{25}$. Uría trabaja también por su parte ; pero como todas estas cosas son aquí tan dificiles - por tener minado el terreno el caciquismo hasta la semana próxima no podrá celebrarse la reunión. En ella figurará ostensiblemente, por lo menos, Buylla. Posada y Sela, no convendrá por

22. J. Costa, Reconstitución y europeización de Españo, Madrid (Imp. de San Francisco de Sales), 1900.

23. Revista critica de Historia y Literatura españolas, Madrid. R. Altamira era el Director de la parte histórica.

24. Basilio Paraiso Lasus. Presidente de la Unión Nacional, de cuyo Directorio formaba Costa parte.

25. La Unión Nacional nació de la fusión de la Liga Nacional de Productores creada por Costa y de las Cámaras de Comercio, capitaneadas por Basilio Paraíso. Las Cámaras Agrícolas calan bajo la jurisdicción de la Liga. La ayuda de Altamira para la formación de la Cámara Agrícola de Asturias es por lo tanto una contribución a la obra de Joaquín Costa. El Uria aquí nombrado es probablemente Enrique Eduardo Uría y Luanco, director de El Eco de Asturias de Oviedo. 
ahora que aparezcan para no suscitar recelos o apoyar argumentos contra la empresa.

Los discursos de Fichte están publicándose en la España Moderna (estamos ya en el xII) y luego se hará tomo aparte. Para la Psicologia del pueblo español no encontré editor. Los de Barcelona no van por ese camino, $\exists$ hay que tener paciencia mientras no se halle un valiente que acometa la obra. El original está siempre a punto.

Recuerdos afectuosos a Tomás y V. sabe le quiere su amigo de siempre.

R. Altamira.

Oviedo 11 Noviembre 1903

Querido Costa : Mil gracias por los libros, que hoy llegaron a mi poder, $\mathbf{J}$ por la carta. Sin esperar el verano, el Resumen ${ }^{20}$ se leerá, y pronto; no sólo por el interés que en sí mismo tiene, sino por el mío particular de escribir un artículo acerca de esa información, tan instructiva y significativa, que a V. debemos, para la revista de Seignobos ${ }^{27}$, L'Européen ${ }^{28}$. No creo que los extranjeros que se preocupan algo por nuestra situación puedan hallar una fuente más abundante y elocuente (por lo menos con referencia a esos que llaman "intelectuales ") para hacerse cargo de nuestro estado mental y volitivo frente a la catástrofe. Hay, en los informes reunidos, y más aún en la Memoria y Resumen de $V$. una cantidad de datos enorme sobre la psicología de la colectividad española; $y$ por eso creo que el libro que $V$. teme no poder llegar a escribir, está ya medio escrito $y$, por mucha que sea la fatiga actual de V., acabará por ser escrito totalmente.

Mi Psicologia - para la que es V. tan benévolo - es una obra incompleta por dos razones. La primera, porque mi propósito, y mi preocupación entonces, eran simplemente probar la aptitud del español para la

26. Se refiere a : Oligarquia y Caciquismo, como la forma actual de gobierno en España : urgencia y modo de cambiarla. Memoria de Sección y resumen de la Información del Ateneo de Madrid sobre dicho tema : Abril-Junio de 1901, Madrid (Imp. de Hijos de M. G. Hernández), 1902.

(Aunque la fecha de impresión en la portada es 1902, en la cubierta es 1903).

27. Charles Seignobos (1854-1942). Célebre historiador francés y prolífico escritor. Fue uno de los miembros más destacados de la escuela de historiadores de finales del siglo $x I x$ que emplearon por primera vez métodos científicos en sus trabajos. Su libro escrito en colaboración con C.-V. Langlois, Introduction aux études historiques (1897) fue durante largos años manual indispensable para el estudioso.

28. L'Européen (1901-1906). No he podido encontrar ningún ejemplar de esta revista en Inglaterra y por tanto ignoro si se publicó o no el artículo al cual se refiere Altamira. - N. D. L. R. : Grâce à l'obligeance de Daniel Devoto qui a bien voulu examiner la collection de $L$ 'Européen conservée à la Bibliothèque nationale de Paris, le Bulletin peut préciser les références des trois seuls articles donnés par Altamira a - la revue de Seignobos ". Il ne semble pas qu'Altamira se réfère ici au troisième et dernier :

$L^{\prime} E u r o p e ́ e n, 2^{\circ}$ année, n० 39, samedi 30 aout 1902, p. 1-2: Psychologie du libéralisme espagnol; $3^{\circ}$ année, n० 20 , samedi 4 avril 1903, p. 1-3: Le catalanisme et les libéraux espagnols; $3^{\circ}$ année, no 106, samedi 12 décembre 1903, p. 1-3:L'Espagne et les catalanistes.

A la question posée par le professeur Cheyne, il faut sans doute répondre par la négative.

Bulletin hispanique. 
cultura, y no sólo descuidé los otros puntos de vista, sino que aún suprimi por completo el capítulo de la psicología actual, para el que tengo reunidas muchas notas. La segunda razón es que, fuera de esa actualidad, a que no me referí más que fragmentariamente, mi opinión es negativa (era, mejor dicho) y por eso plantée críticamente la cuestión : $1^{\circ}$ negando valor cientifico a las psicologias que hasta entonces se habian formulado, por españoles y extranjeros ; $2^{\circ}$ afirmando que, mientras no se estudiasen las fuentes todas cuya enumeración hacia y se conociese más a fondo la historia de España, era imposible decir nada definitivo. Hay además otro punto de vista, a que aludí muy de pasada : el de los catalanes, para quienes no hay psicología del pueblo español, sino del catalán, aragonés, castellano, etc., todo ello porque se creen de raza (?) superior a los otros y se tienen (o aparentan tencrse) por irresponsables de la decadencia y del estado actual. Esto hay que discutirlo y refutarlo de una vez para todas, porque sólo procede del orgullo catalán insufrible $y$ pedante.

A V., querido Costa, le corresponde de derecho escribir ese libro que, repito, ya tiene $V$. medio redactado. Será un servicio más (no el último, por fortuna) que deberá a V. el país y dentro de él, especialmente, los que somos sus discipulos directos, pero carecemos de fuerza para continuar como es debido la obrá del maestro.

Tengo ahora en el telar dos cosas que ya conocerá V. : el tomo $3^{\circ}$ de la Historia (que me preocupa mucho) y varios informes para el Congreso de historiadores que se celebrará en Roma el próximo abril.

Gracias de nuevo por todo.

Le quiere siempre y le abraza su amigo.

R. Altamira.

Quisiera expresar mi sincera gratitud al Profesor O. N. V. Glendinning por su gentileza al facilitarme la relación de los datos de La España Moderna como también al Research Committee de la Universidad de Newcastle upon Tyne por su ayuda en mis investigaciones sobre J. Costa.

G. J. G. CHEYNE. 